Meta

Journal des traducteurs

Translators' Journal

\title{
Meta : de journal des traducteurs à revue scientifique
}

\section{Marc Pomerleau}

Volume 60, numéro 2, août 2015

$60^{\mathrm{e}}$ anniversaire. Les horizons de la traduction : retour vers le futur

$60^{\text {th }}$ Anniversary. Translation's Horizons: Back to the Future

60mo aniversario. Los horizontes de la traducción: regreso al futuro

URI : https://id.erudit.org/iderudit/1032916ar

DOI : https://doi.org/10.7202/1032916ar

Aller au sommaire du numéro

Éditeur(s)

Les Presses de l’Université de Montréal

ISSN

0026-0452 (imprimé)

1492-1421 (numérique)

Découvrir la revue

Citer ce document

Pomerleau, M. (2015). Meta : de journal des traducteurs à revue scientifique. Meta, 60(2), 365-365. https://doi.org/10.7202/1032916ar d'utilisation que vous pouvez consulter en ligne.

https://apropos.erudit.org/fr/usagers/politique-dutilisation/ 


\title{
Meta: de journal des traducteurs à revue scientifique
}

\author{
Marc Pomerleau \\ Université de Montréal, Montréal, Canada \\ marc.pomerleau@umontreal.ca
}

\begin{abstract}
Au cours des soixante dernières années, le Journal des traducteurs Meta a grandement évolué. Cette communication propose un regard historique, à l'occasion ludique, sur la façon dont s'est transformé Meta au fil des ans. À la suite d'une recherche archivistique, nous présentons quelques numéros spéciaux, des articles aux thèmes parfois surprenants, d'anciennes chroniques et rubriques oubliées, de même que des portraits de collaborateurs. Nous soulignerons également le travail accompli au fil des ans par les diverses équipes et comités de la revue, en prenant soin de nous attarder sur les pionniers et sur les hommes et femmes qui ont tenu Meta haut et fort au fil du temps. Par ailleurs, nous suivrons l'apparition de concepts clés en traductologie et de nouveaux domaines de recherche, comme la traduction culturelle, le multilinguisme et la traduction assistée par ordinateur. Nous nous attarderons également à l'évolution graphique de la revue, aux publicités de jadis et aux commanditaires. En somme, nous verrons comment a évolué Meta, autrefois véritable journal des traducteurs d'ici, devenu aujourd'hui revue scientifique de traductologie de renommée internationale. L'évolution de Meta et du contenu de ses pages depuis 1955 nous offre une lucarne privilégiée sur l'évolution de la recherche traductologique et des professions langagières.
\end{abstract}

Traducteur agréé, Marc Pomerleau occupe le poste d'assistant à l'édition à la revue Meta. Détenteur d'un B.A. assorti d'une majeure en études latino-américaines et d'un DESS en traduction de l'Université McGill, il a également obtenu une maîtrise en traduction de l'Université de Montréal, sous la direction de Georges L. Bastin, avec qui il prépare une thèse doctorale sur la traduction politique en Catalogne. Chargé de cours à l'Université de Montréal, il a également enseigné à l'Université de Brasília. Parmi ses récentes publications, notons « De la traducción cultural a la auto-tradaptación» dans Tinkuy (2015), «Indépendance de la Catalogne: quand la traduction se mêle du débat» dans Dire (2014), «Le galicien, une langue prise en étau? » dans Belas Infiéis (2013), et l'entrée «Francisco Ximénez» dans le Diccionario histórico de la traducción en Hispanoamérica (2013), dirigé par Francisco Lafarga et Luis Pegenaute. 